\title{
OPTIMAL GOVERNMENT SPENDING AND TAXATION IN ENDOGENOUS GROWTH MODELS
}

\author{
Giancarlo Corsetti \\ Nouriel Roubini
}

Working Paper 5851

\section{NATIONAL BUREAU OF ECONOMIC RESEARCH 1050 Massachusetts Avenue \\ Cambridge, MA 02138 \\ December 1996}

We thank participants in the 1996 CEPR European Symposium on Macroeconomics and a seminar at Yale University for helpful comments. This paper is part of NBER's research program in Public Economics. Any opinions expressed are those of the authors and not those of the National Bureau of Economic Research.

(C) 1996 by Giancarlo Corsetti and Nouriel Roubini. All rights reserved. Short sections of text, not to exceed two paragraphs, may be quoted without explicit permission provided that full credit, including $(\mathcal{C}$ notice, is given to the source. 
Optimal Government Spending and Taxation

in Endogenous Growth Models

Giancarlo Corsetti and Nouriel Roubini

NBER Working Paper No. 5851

December 1996

JEL Nos. E62, O41

Public Economics

\section{ABSTRACT}

This paper analyzes optimal spending, tax and financial policies in models of endogenous growth where public spending is productive. We extend previous work in four directions. First, we analyze optimal policies when the government is allowed to borrow and lend, rather than being restricted to run a balanced budget in every period. Second, we develop a model with a separate human capital accumulation sector. Therefore, the properties of optimal policies depend on whether government spending affects the productivity of the final goods sector or the human capital accumulation sector. Third, we consider the policy implications of alternative assumptions about which factor of production benefits from the external effects of productive public goods. Fourth, we study the implications of restrictions on the menu of tax instruments available to the policy maker. We contrast optimal tax rates on human and physical capital under different assumptions on technology and distribution. We analyze the welfare properties of public debt and assets.

Giancarlo Corsetti

Department of Economics

Yale University

37 Hillhouse Avenue

New Haven, CT 06520

corsetti@econ.yale.edu
Nouriel Roubini

Department of Economics MEC 7-83

Stern School of Business

New York University

44 West 4th Street

New York, NY 10012

and NBER

nroubini@stern.nyu.edu 


\section{Introduction}

Economists have debated for a long time the effects of government spending on economic growth. If government spending is assumed to be unproductive (as in many formal analyses of the effects of fiscal policy) while tax rates are assumed to be distortionary, higher government spending generally leads to lower long-run per capita income - according to the neoclassical growth theory - or to lower long-run growth - according to endogenous growth models. Such predictions clash with the growing empirical evidence that higher government spending and taxes (relative to the size of the economy) are not negatively correlated with the growth rate. A simple way to interpret such results is to observe that the paradigm of government spending as useless and unproductive consumption of economic resources is naive and imprecise. Many forms of public spending are actually directly or indirectly productive, and affect the productivity of the economy in different ways.

Once we recognize that public spending can be productive, the theoretical prediction of a negative relation between tax rates and growth is weakened. If higher distortionary taxes are used to finance a higher productive public spending, the larger scale of government activities may actually enhance the growth rate, despite the negative effect on growth of taxation. At a theoretical level, such a point has been payed renewed attention in a number of studies starting with Barro [1990] (see also Arrow and Kurz [1970] for an early reference). At an empirical level, several authors have shown that the relation between public investment expenditures and long-run growth is positive (see Easterly and Rebelo [1994] for a recent empirical study).

While recent studies on productive government spending and growth have provided important insights on the link between fiscal variables and the long run performance of the economy, the literature has so far paid little attention to a number of important issues. First, many authors have addressed the normative analysis of spending and taxation policies under the constraint that the government budget be balanced in every period (see Barro [1990] and Barro and Sala$\mathrm{i}$-Martin $[1992,1995])$. This approach leaves open the issue of determining the unconstrained long-run optimal policy, that may require intertemporal borrowing and lending by the public sector. Second, most contributions on the growth effects of productive public spending restricted their analysis to one-sector models, where public spending can only affect the productivity of the final goods sector. Given 
the important role of public spending in education, health, scientific research and $\mathrm{R} \& \mathrm{D}$, one should consider models where public spending can also affect the productivity of the sectors producing knowledge and human capital, so as to trace the economic implications of spending resources on alternative public goods. Third, previous work has generally assumed that productive public spending either exerts a positive externality on the productivity of labor or generates rents that are appropriated by a fixed factor. However, the public spending may be also have an external effect on the productivity of physical capital. Which factor of production benefits from the external effects of a productive public spending is an empirical issue. There are no obvious reasons, on either logical or empirical grounds, why this factor should be labor, as is commonly assumed. Clearly, different assumptions on this issue will crucially affect the design of the optimal tax and spending policy. Fourth, many contributions have arbitrarily restricted the menu of tax instruments focusing exclusively on income taxes.

In this paper we reconsider the effects of an endogenous and productive government spending in endogenous growth models. We extend previous work in four directions. First, we do not impose a balanced budget in every period; thus we are able to address optimal intertemporal taxation problems. Second, we develop a model with a separate human capital accumulation sector; we can therefore consider cases where government spending affects the productivity of either the final goods sector or the human capital accumulation sector (or both). Third, we explicitly address an issue finessed by Barro [1990], i.e. which factor of production is affected by the external effects of productive public spending. In principle, such external effects may be on human or physical capital; we consider both cases. Fourth, we allow for a broader set of tax instruments including different tax rates on the income of the various factors; we discuss next the implications of restricting this menu of taxes as in the case of an income tax.

The long-run optimal taxation of human and physical capital is quite different from the results commonly found in one-sector models where the budget is balanced and spending-related rents are appropriated by some fixed factor of production. In general, the presence of productive public goods suggests the efficiency of non-lump sum taxes or subsidies, aimed at correcting relative prices. Taxes on capital or labor income are not necessarily distortionary, as an optimal policy may consist of a set of Pigouvian taxes and subsidies.

When the set of tax instruments available to the policy makers is sufficiently large, the optimal plan requires the budget to be balanced both in the short and in the long run, making public debt and assets redundant as policy tools. Public 
debt or asset may not be redundant, however, when there are constraints on the set of the tax instruments available to the policy makers. A relevant example is when the income from human capital and the income from physical capital cannot be taxed separately, as is the case with income taxes. We will show that in two popular models of endogenous growth, despite restrictions on the set of policy instruments, there exists an optimal policy that will replicate the first best growth rate and factor allocations in the long run, provided that the policy maker can resort to public borrowing and lending to smooth distortions over time.

Our results on optimal taxation and spending are related to work by Barro[1990], Barro and Sala-i-Martin [1992, 1995], Jones, Manuelli and Rossi [1993], Corsetti [1992, 1995, 1997], Judd [1995a,b], Zhu [1992], and Glomm and Ravikumar [1993, 1994] among others. Relative to this literature, our model provides an efficient taxonomy of model specifications. Several contributions can be nested in our general multi-sector model depending on whether 1) government spending has an external effect on either the production of final goods or the production of human capital, 2) the external effects of government-spending increase the productivity of either physical or human capital, 3) there are constraints on the set of policy instruments and 4) the government is allowed to borrow and lend in the financial markets. Our scheme will therefore allow us to highlight which specific assumptions on these four issues drive the results obtained in previous contributions. As in most of the literature, we restrict our analysis to services from a productive government spending flow, rather than a stock of public infrastructure. ${ }^{1}$

The structure of the paper is the following. In section 2 we present the model, characterize the competitive equilibrium and discuss some features of the market equilibrium on a balanced-growth path, with special reference to the role of tax rates (on human and physical capital) and of government spending. Section 3 presents the normative analysis of the optimal government spending and taxation, with or without constraint on the menu of available taxes. Using our model as a common framework, in section 4 we carry out an analytical survey of the literature that relates our results to those in previous contributions. Section 5 presents some concluding remarks.

\footnotetext{
${ }^{1}$ Glomm and Ravikumar [1994a, 1994b] present variants of a model where public investment in infrastructures is an input in the production of final goods. They model public infrastructures in a number of ways: as subject to congestion or not; as non-exclusive but exhibiting different degrees of non-rivalry. They they limit the analysis to the case of uniform taxes on capital and labor income. Compared to our work, they do not allow for borrowing and lending, do not distinguish for the possibility that rents may be appropriated by either labor and capital and consider externalities only in final goods.
} 


\section{Public spending as a productive input: a model}

In this section we present a three-sector model of endogenous growth, including both physical and human capital as factors of production. The first sector produces final output that can be consumed or accumulated (physical capital), the second sector produces human capital, while the third sector is the home production sector.

Previous models of "endogenous" government spending (Barro [1990] and Barro and Sala-i-Martin [1992, 1995]), have restricted government spending to be an input only in the production of the final good sector. By building a model with a human capital accumulation sector and a home production sector, we are able to analyze more general specifications, where public spending affects the productivity of different activities. In this paper, we focus on two alternative specifications: in the first, public spending is an input in the final goods sector only; in the other, it is an input in the human capital accumulation sector only.

The effect of public spending in the production of market goods can be exemplified by the services provided by the judicial and police systems that enforce laws and contracts and have an external effects on market transactions. Public spending as an input in the human capital production function consists of the supply of services (such as public education) that directly contribute to the accumulation of human capital. In practice, as regards their effects on productivity, it may be difficult to keep the two kinds of spending separated from each other. We will nonetheless consider them one at a time, in order to highlight the positive and normative implications of sector-specific public spending.

\subsection{Aggregate Production Functions}

We start by specifying the aggregate social production function for each sector in the economy. These functions should be viewed as reduced forms corresponding to a variety of technologies that firms and/or individual households face in a decentralized economy - as those described in Appendix A.

From a social point of view, final output, human capital and home goods are all produced with constant return to scale to all inputs. Inputs are physical capital $(\mathrm{K})$, human capital $(\mathrm{H})$ and public goods $(\mathrm{G})$. We assume a specific functional form, using Cobb-Douglas production functions.

The aggregate production function for final output $Y$ can be written as

$$
Y_{t}=A\left(v_{t} K_{t}\right)^{\alpha \epsilon}\left(u_{t} H_{t}\right)^{1-\alpha}\left(G_{t}\right)^{\alpha(1-\epsilon)}
$$


where $v$ and $u$ are, respectively, the fraction of total physical and human capital devoted to production of final goods. ${ }^{2}$ The productivity of public spending is decreasing in the parameter $\epsilon$. For $\epsilon=1$, public goods is not a required input in the production of final goods. In that case, (2.1) is a standard Cobb-Douglas in $\mathrm{K}$ and $\mathrm{H}$. Note that, at the aggregate level, the public good is non-excludable but, with constant returns to scale to the three inputs, rival.

As the capital stock is assumed to depreciate at the instantaneous rate $\delta$, the resource constraint for the final goods sector is

$$
\dot{K}_{t}=Y_{t}-\delta K_{t}-C_{t}-G_{t}
$$

where $C$ is private consumption.

The production function for human capital is

$$
\stackrel{\bullet}{H}_{t}=B\left(x_{t} K_{t}\right)^{\beta \omega}\left(z_{t} H_{t}\right)^{1-\beta}\left(G_{t}\right)^{\beta(1-\omega)}-\delta H_{t}
$$

where $x$ and $z$ are, respectively, the fraction of physical and human capital devoted to the accumulation of human capital. The productivity of public spending is a decreasing function of the parameter $\omega$. For $\omega=1$, public goods do not provide services that are required in the production of human capital and (2.3) becomes a standard Cobb-Douglas in $\mathrm{K}$ and $\mathrm{H}$. Note that both human and physical capital are assumed to depreciate at the same rate $\delta$.

The home production sector, which uses the remaining fractions of both physical and human capital, is characterized by the following production function

$$
L_{t}=\left[\left(1-v_{t}-x_{t}\right) K_{t}\right]^{\gamma}\left[\left(1-u_{t}-z_{t}\right) H_{t}\right]^{1-\gamma}
$$

Here the L activity is interpreted as "home" production but, as in Milesi-Ferretti and Roubini [1994a, 1994b], we can also think of it as a non-market "leisure" good, producing which requires both human and physical capital.

While $G$ may enter the production functions of different sectors at the same time, in this paper we rule out the possibility that public spending affects the productivity in the home production sector and focus on two extreme alternative cases: either $\epsilon>0$ and $\omega=0$ ( $G$ only enters the production of final goods), or $\epsilon=0$ and $\omega>0$ ( $\mathrm{G}$ only affects the accumulation of human capital).

\footnotetext{
${ }^{2}$ We have implicitly assumed that the "point in time technology" are linear: if the fraction $v$ of the capital stock is employed in the production of final good, the capital input in production is $v K$. This assumption is not necessary for our result. Mulligan and Sala-i-Martin [1993] provide a detailed discussion of the "point in time technology".
} 


\subsection{Spending-related externalities, production and distribution}

Expressions (2.1) through (2.4) describe the available technology from a social point of view. In a competitive equilibrium, private firms will face a different set of technologies, depending on which factor of production benefits from the spending-related externality. The existence of such external effects clearly creates a problem of efficiency of the market allocation. Moreover, as the presence of public spending exerting an external effect in production generates rents, it also raises a distributional issue. For instance, consider the case in which $G$ is an input in the production of final output $(Y)$, and its external effect raises the productivity of human capital. The reward to human capital will then include the pure rents deriving from the contribution of public spending to production: the private return to human capital will be above its social return.

For the sake of simplicity we will analyze market allocations in which the external effect of government spending raises the productivity of only one factor of production, so that spending-related production rents go to either human capital or physical capital. ${ }^{3}$ Under the assumption that $\mathrm{G}$ can be a productive input either in the final output sector or in the human capital sector, our two extreme externality assumptions yield the following four-way typology of models ${ }^{4}$

\footnotetext{
${ }^{3}$ One could alternatively assume that, in the background of th model, there is another factor in fixed supply, in addition to the reproducible factors $\mathrm{K}$ and $\mathrm{H}$, and that this fixed factor appropriates the pure rents generated by the existence of government spending related externalities. We do not find such an approach appealing for three reasons. First, it appeals to a fixed factor that is introduced in the model in an ad-hoc way only to acquire the G-related rents. Second, while it might make sense to assume that a fixed factor appropriates pure profits in models without externalities, it is not clear why one should assume a prori that such rents are appropriated by the fixed factor (rather than the variable ones) in models where such rents are caused by the existence of public spending that has an external effect in production. Third, while the existence of a fixed factor that appropriates the rents would imply that there is no divergence between private and social returns to reproducible factors $\mathrm{K}$ an $\mathrm{H}$, it would lead to such a divergence for the fixed factor as its social return is zero while its private return is positive.

${ }^{4}$ One could alternatively assume that, in the background of the model, there is another factor in fixed supply, in addition to the reproducible factors $K$ and $H$, and that this fixed factor appropriates the pure rents generated by the existence of government spending related externalities. We do not find such an approach appealing for three reasons. First, it appeals to a fixed factor that is introduced in the model in an ad-hoc way only to acquire the G-related rents. Second, while it might make sense to assume that a fixed factor appropriates pure profits in models without externalities, it is not clear why one should assume a priori that such rents are appropriated by the fixed factor (rather than the variable ones) in models where such rents are caused by the existence of public spending that has an external effect in production. Third,
} 
Externalities:

$\mathrm{G}$ affects the productivity of physical capital

$\mathrm{G}$ affects the productivity of human capital
Table 1

Technology:

$G$ in final output sector $G$ in human capital sector

Model 1

Model 3

Model 2
Model 4

The productive public spending $G$ can be thought of as encompassing very different types of publicly provided goods and services, such as justice, enforcement of law and contracts, police services, educational services and government research activities.

As an example of how the same public good might affect the productivity of either final goods and/or human capital accumulation consider the case of Internet services. Model 1 and 2 state that Internet services only affect the productivity of the final output sector. Models 3 and 4 state that Internet services are a required input only in the educational and research activities. Take the latter case first. We could imagine that government provided Internet services are only accessible to academic and research institutions (as it was originally the case for the Internet). As captured by Model 3, the universities' computers become more productive because of the Internet. On the other hand, if the government provides free Internet services to the firms only, as in Model 1, then their capital goods (their computers) would be more productive thanks to the free appropriation of communication services.

Model 4 is more relevant for publicly provided goods such as educational expenditures and basic government research that increase the knowledge and human capital of individuals while they are involved in educational activities. In this case the externality effect of $\mathrm{G}$ are on "human capital". Model 2 best describes the case of government-sponsored training of workers and apprenticeship programs, government-provided health and safety services that increase the productivity of workers while involved in production activities. ${ }^{5}$

while the existence of a fixed factor that appropriates the rents would imply that there is no divergence between private and social returns to reproducible factors $K$ an $H$, it would lead to such a divergence for the fixed factor as its social return is zero while its private return is positive.

${ }^{5}$ Note that, while we do not consider in the model government services that affect the production of leisure (home production), one can of course think of several examples in which this is indeed the case. Think of public amenities such as national parks and environmental expenditures in general. 
In the final output sector, firms rent capital at the market rate $R_{t}^{K}$ and pay labor at the current wage rate $R_{t}^{H}$. They hire labor and capital up to the point where their marginal cost is equal to their privately perceived marginal product. In the human capital accumulation sector, the returns to physical capital $\rho^{K}$ and the return to human capital $\rho^{H}$ can instead be computed as shadow-values, allowing for specific externality assumptions. According to our typology, we obtain the following equilibrium market prices:

\section{Table 2.1}

$\begin{array}{lll} & R^{K} & R^{H} \\ \text { Model 1 } & \alpha A\left(\frac{v K}{u H}\right)^{\alpha-1}\left(\frac{G}{v K}\right)^{\alpha(1-\epsilon)} & (1-\alpha) A\left(\frac{v K}{u H}\right)^{\alpha}\left(\frac{G}{v K}\right)^{\alpha(1-\epsilon)} \\ \text { Model 2 } & \epsilon \alpha A\left(\frac{v K}{u H}\right)^{\alpha-1}\left(\frac{G}{v K}\right)^{\alpha(1-\epsilon)} & (1-\epsilon \alpha) A\left(\frac{v K}{u H}\right)^{\alpha}\left(\frac{G}{v K}\right)^{\alpha(1-\epsilon)} \\ \text { Model 3 } & \alpha A\left(\frac{v K}{u H}\right)^{\alpha-1} & (1-\alpha) A\left(\frac{v K}{u H}\right)^{\alpha} \\ \text { Model 4 } & \alpha A\left(\frac{v K}{u H}\right)^{\alpha-1} & (1-\alpha) A\left(\frac{v K}{u H}\right)^{\alpha}\end{array}$

$$
\begin{array}{lll} 
& \rho^{K} & \rho^{H} \\
\text { Model 1 } & \beta B\left(\frac{x K}{z H}\right)^{\beta-1} & (1-\beta) B\left(\frac{x K}{z H}\right)^{\beta} \\
\text { Model 2 } & \beta B\left(\frac{x K}{z H}\right)^{\beta-1} & (1-\beta) B\left(\frac{x K}{z H}\right)^{\beta} \\
\text { Model 3 } & \beta B\left(\frac{x K}{z H}\right)^{\beta-1}\left(\frac{G}{x K}\right)^{\beta(1-\omega)} & (1-\beta) B\left(\frac{x K}{z H}\right)^{\beta}\left(\frac{G}{x K}\right)^{\beta(1-\omega)} \\
\text { Model 4 } & \omega \beta B\left(\frac{x K}{z H}\right)^{\beta-1}\left(\frac{G}{x K}\right)^{\beta(1-\omega)} & (1-\omega \beta) B\left(\frac{x K}{z H}\right)^{\beta}\left(\frac{G}{x K}\right)^{\beta(1-\omega)}
\end{array}
$$

Table 2.2

As mentioned before, Appendix A provides a detailed discussion of firm-level techologies that correspond to the rate of return included in these tables.

\subsection{The government budget}

The government faces two sets of decisions. First, it has to decide the amount of public goods to be provided to the economy. Second, it needs to finance the path of spending, using factor income taxation and/or borrowing. Denoting with $\tau^{K}$ and $\tau^{H}$ the tax rates on capital and labor income respectively, total tax revenues can be written as

$$
T_{t}=\tau_{t}^{K} R_{t}^{K} v_{t} K_{t}+\tau_{t}^{H} R_{t}^{H} u_{t} H_{t}
$$

Without loss of generality we assume that government bonds are tax-exempt. The instantaneous budget constraint faced by the government is given by

$$
\dot{B}_{t}=r_{t} B_{t}+G_{t}-T_{t}
$$


where $B_{t}$ are government bonds, $r_{t}$ is the rate of interest and $T_{t}$ is total tax revenues. The usual no-Ponzi-game condition applies.

\subsection{Private agents}

The economy is inhabited by identical atomistic agents. They choose consumption, investment and the allocation of their human and physical capital with the purpose of maximizing an intertemporal utility function:

$$
U=\int_{0}^{\infty} e^{-\rho t}\left(\frac{\left(C_{t} L_{t}^{\eta}\right)^{1-\theta}}{1-\theta}-1\right) d t
$$

where $\rho$ is the rate of time preference; the instantaneous utility function takes a Constant Intertemporal Elasticity of Substitution (CIES) form, with $\theta$ being the inverse of the intertemporal elasticity of substitution. The utility function is similar to the one in Benhabib, Rogerson and Wright [1991]. Here home production can be interpreted as a form of "leisure", as in Greenwood and Hercowitz [1991]. A special case of this occurs when $\gamma=0$, so that leisure is "quality time" as in Rebelo [1991].

Consumers maximize their utility (2.7) subject to the constraint on human capital accumulation (2.3), to the home production technology (2.4) and to the consumer's budget constraint:

$$
R_{t}^{K}\left(1-\tau_{t}^{K}\right) v_{t} K_{t}+R_{t}^{H}\left(1-\tau_{t}^{H}\right) u_{t} H_{t}+r_{t} B_{t}-C_{t}-\dot{B}_{t}-\dot{K}_{t}-\delta K_{t} \geq 0
$$

\subsection{Market allocation}

In all four specifications, the economy will exhibit a balanced-growth path, along which consumption, physical and human capital grow at the same rate, while factor allocation $(u, v, x$ and $z)$ remain constant. As shown in Appendix A, this growth rate is

$$
\frac{\dot{C}}{C}=\frac{1}{\theta-\eta(1-\theta)}\left[R^{K}\left(1-\tau^{K}\right)-\delta-\rho\right]
$$

where the time subscript have being omitted, as we are considering the balancedgrowth path. 6

\footnotetext{
${ }^{6}$ Note that, in order to get bounded utility, we need to have parameter values such that utility does not grow faster than the rate of time preference. This requires the following condition:

$$
r-\delta<\frac{\rho}{(1+\eta)(1-\theta)}
$$
}


Since the external effects are specific to each of the four models, we describe the solution for the balanced-growth path in each specification. A general form for the constant growth rate is

$$
\frac{\dot{C}}{C}=\frac{1}{\theta-\eta(1-\theta)}\left[A_{i} \Gamma_{i}\left(1-\tau^{K}\right)^{\beta \alpha}\left(1-\tau^{H}\right)^{\beta(1-\alpha)}-\delta-\rho\right]^{\frac{1}{1-\alpha+\beta}}
$$

where the expressions $A_{i}$ and $\Gamma_{i}$, that are model-specific, are given in the following table:

\begin{tabular}{llll} 
& \multicolumn{1}{c}{ Table 3 } & \multicolumn{1}{c}{$\Gamma_{i}$} \\
Model 1 & {$\left[\left(\frac{\alpha}{1-\alpha} \frac{1-\beta}{\beta}\right)^{\beta(\alpha-1)} \frac{(\alpha A)^{\beta}}{[(1-\beta) B]^{\alpha-1}}\right]$} & $\left(\frac{G}{v K}\right)^{\alpha \beta(1-\epsilon)}$ \\
Model 2 & $\left.\left(\frac{\epsilon \alpha}{1-\epsilon \alpha} \frac{1-\beta}{\beta}\right)^{\beta(\alpha-1)} \frac{(\epsilon \alpha A)^{\beta}}{[(1-\beta) B]^{\alpha-1}}\right]$ & same as 1 \\
Model 3 & $\left.\left(\frac{\alpha}{1-\alpha} \frac{1-\beta}{\beta}\right)^{\beta(\alpha-1)} \frac{(\alpha A)^{\beta}}{[(1-\beta) B]^{\alpha-1}}\right]$ & $\left(\frac{G}{x K}\right)^{(1-\alpha) \beta(1-\omega)}$ \\
Model 4 & $\left.\left(\frac{\alpha}{1-\alpha} \frac{1-\omega \beta}{\omega \beta}\right)^{\beta(\alpha-1)} \frac{(\alpha A)^{\beta}}{[(1-\omega \beta) B]^{\alpha-1}}\right]$ & same as 3
\end{tabular}

It is worthwhile to point out three features of the models. First, the return to physical capital and growth are positively related to each other provided that the intertemporal elasticity of substitution is sufficiently low: $\theta-\eta(1-\theta)>0)$. This inequality will be a maintained assumption in what follows.

A second feature of the model is that the balanced-growth path is independent of tax rates on human and physical capital when $\beta=0$, i.e. when human capital accumulation does not require physical capital inputs (as in Lucas [1988]). ${ }^{7}$ Conversely, for a strictly positive $\beta$ (physical capital is an input in the production of human capital), higher tax rates on either factor of production have a negative effect on growth (see Milesi Ferretti and Roubini $[1994 a, b]) .^{8}$

\footnotetext{
${ }^{7}$ This exercise is carried out under the assumption that the public debt to capital ratio along the balanced growth path adjust so as to ensure solvency of the public sector.

${ }^{8}$ Milesi-Ferretti and Roubini [1994a] discuss the intuition behind the independence of growth from taxes in Lucas type of growth model where human capital is produced only with human capital. Note also that the independence of growth from the tax on human capital when $\beta=0$ does not hold when the human capital sector is a market sector whose inputs can be taxed; see Milesi-Ferretti and Roubini [1995] for a discussion of this point.
} 
A third feature of the model is that, for given tax rates and for a strictly positive $\beta$, the balanced-growth rate is a positive function of the public spendingto-capital ratio in all four models. This result follows from (2.10) and Table 3. An intuitive explanation of this property is as follows. For given tax rates, the magnitude of tax-induced distortions in the economy is constant, while more resources are channeled into the supply of productive services by the public sector; therefore, the growth rate of the economy is higher. Note that, for given tax rates and a higher spending rate, the solvency constraint requires a lower long-run stock of public liabilities (a higher stock of public asset).

\section{Optimal policy when the public good is an input in the production of final output}

In this section we address the normative issue of identifying the optimal spending path and financial policy from the stand point of a benevolent government. A formal analysis of this problem requires the solution of a "Ramsey planner problem" where the government chooses the path of government spending, tax rates and bonds with the goal of maximizing the representative agent's welfare, taking the market allocation conditions as constraints. One approach to this problem is as in Chamley [1986]: the government chooses taxes and spending as to maximize the consumer's indirect utility function, subject to the economy resource constraint and the government budget constraint. A different approach, as in Lucas and Stokey [1983], consists of formulating the government problem as a "restricted Ramsey planner" problem, where the government chooses quantities directly, subject to the consumer's intertemporal budget constraint and consistent with the market allocation of physical and human capital. ${ }^{9}$

Before addressing the problem of designing the optimal fiscal policy, it is important to stress the difference between the class of model(s) under consideration, where public spending is productive and its size is chosen by the policy makers, and models where the path of public consumption is exogenously given and has no effect on production. Typically, in the second type of models, the only distortions

\footnotetext{
${ }^{9}$ The constraints of the problem are derived from the consumer's first order conditions. These, together with the firm's optimality conditions, are used to eliminate factor returns and tax rates from the constraint so as to express the problem in terms of quantity only. The optimal quantities chosen by the government will then implicitly determine tax rates and factor returns. This is the approach followed by Lucas [1990], Chari, Christiano and Kehoe [1994], Jones, Manuelli and Rossi [1993,1996], Milesi Ferretti and Roubini [1994a, 1995], among others.
} 
in the economy are induced by tax instruments. A set of well known results in the literature establish that, as an application of the Ramsey rule in an intertemporal setting, the optimal long-run tax rate on reproducible factors is zero. That is to say, in models that allow for both human and physical capital, the optimal longrun tax rates on both factors' income is zero (Jones, Manuelli and Rossi [1993] and Milesi-Ferretti and Roubini [1994a]). The key feature of an economy with an optimal policy in place is a positive net financial wealth for the public sector in the long run, serving to finance government spending. The benefits from reducing or eliminating tax-related distortions in the long run exceed the short-run costs of accumulating public assets.

A result stating the optimality of creditor states of course raises a number of questions, first and foremost regarding the reasons why we do not observe such a program implemented in practice. A positive analysis of this issue require more general models, allowing for imperfect information and suitable for analyzing time-consistency of both private and public optimal plans. Nonetheless, it should be stressed that the optimality of creditor states characterizes a broad class of (popular) growth models. ${ }^{10}$

In the models analyzed in this paper, the public good nature of government spending induces distortions in the economy independently of the tax instruments available to the government. This feature suggest that the interplay of spending and tax distortions may lead to optimal plans that do not require the use of public debt or assets. Consistently, in what follows, we will first show that a government endowed with enough tax instruments has no need to engage in intertemporal tax strategies, involving borrowing or lending. We will then discuss the role of intertemporal tax strategies in the presence of constraints on the set of available taxes. In doing so, we will mainly focus on the case where government spending affects only the productivity of the market sector.

\subsection{Optimal government spending}

The problem faced by the government is one of choosing optimally both spending and taxes. For what concerns the first choice, the solution of the government problem has spending being a constant fraction of output, irrespectively of whether the external effects of spending in production are on human or physical capital.

\footnotetext{
${ }^{10}$ In Corsetti and Roubini [1996], we provide a systematic analysis of implementing optimal policies requiring the a positive net asset position for the government. Specifically, we consider the possibility of implementing first best policies through the use of "tax certificates".
} 
Proposition 1. When government spending is an input in production of final output ( $\epsilon>0$ and $\omega=0$ ), the optimal choice of government spending implies a constant ratio of spending to output in every period, regardless of the tax policy implemented by the government. This ratio is equal to

$$
\frac{G}{Y}=\alpha(1-\epsilon)
$$

Proof: see Appendix B.

The optimal provision of public goods in both model 1 and 2 solves a static efficiency problem. The marginal cost of public spending in terms of foregone final output is equal to 1 , while its marginal product is $\frac{\partial Y}{\partial G}=\alpha(1-\epsilon) \frac{Y}{G} \cdot{ }^{11}$ Even if the tax rate is set at a suboptimal value, there is no room for a second-best argument advocating a change in the spending rate out of income. The reason is that (3.1) can be interpreted as an arbitrage condition. The arbitrage is implicit in the specification of technology: for any $\frac{G}{Y}$ lower than the optimal one, an extra unit of spending generates more than one unit of output. ${ }^{12}$

\subsection{Optimal taxation with different tax rates on human and physical capital income}

Next, what will be the optimal tax and financial policy? The core-feature of the model is the presence of externalities in production, that create a wedge between private and social prices. At an optimum, tax rates serve two purposes: one is to finance spending, the other one is to correct the public-spending induced distortions in the private economy. Provided that the government is endowed with enough tax instruments, it will then be possible to design policies supporting a first best allocation. In the simplest case, it turns out that the models of government spending and growth under consideration lead to an application of Pigouvian taxes. This is stated by the proposition below.

\footnotetext{
${ }^{11}$ This result can also be derived in the one sector endogenous growth model discussed by Barro [1990] and Barro and Sala-i-Martin [1992]. Because of the assumption of an instantaneously balanced budget in these papers, the result is referred to as the (second best) optimal choice of the tax rate. It should be properly regarded as a result concering the optimal choice of spending, that holds with and without distortionary taxation.

${ }^{12}$ In Corsetti $[1992,1997]$, uncertainty leads to a reformulation of such an arbitrage condition in terms of risk-adjusted values of spending.
} 
Proposition 2. $\quad$ Consider the case in which government spending is an input in the production of final goods. If government spending exerts an external effect on physical capital (model 1), the optimal tax on human capital income is always zero $\left(\tau^{H}=0\right)$ while the optimal tax on physical capital income is always positive, and equal to $\tau^{K}=(1-\epsilon)$. If the external effect is on human capital (model 2), the optimal tax on human capital income is always positive and equal to $\tau_{t}^{H}=\frac{\alpha(1-\epsilon)}{1-\epsilon \alpha}$, while the optimal tax on physical capital income is equal to zero $\left(\tau_{t}^{K}=0\right)$. In both models, the optimal tax policy supports the first-best allocation.

\section{Proof: See Appendix B.}

The intuition for the result is the following. Differently from the two sector model without externalities, the private and the social rate of return to physical (human) capital diverge when the government spending affect the productivity of physical (human) capital. The private rate of return is above the social rate, and a standard Pigouvian tax on the factor income is then required to equalize the two rates of return. The optimal tax policies in model 1 and 2 are symmetric, in the sense that the factor that is affected by $G$ taxed, while the other factor is not taxed at all. ${ }^{13} 14$

\footnotetext{
${ }^{13}$ We can also think of the optimal spending and tax plan as the imposition of a "user fee" on the provision of a public good. Public spending is effectively a public input in the production of private goods. If such a good was excludable, public finance principles would require the optimal imposition of a user fee to be paid by the firm using such a factor of production (public service). Here, the public good is assumed to be non-excludable ruling out the possibility of a formal user fee. However, the tax on the income of the factor that appropriates the rents generated by the public input turns out to be equivalent to a "user fee" in case the public good had instead been assumed to be excluable.

${ }^{14}$ If we had introduced in the model an additional factor in fixed supply and assumed that such factor was appropriating all G-related rents, the optimal tax policy would imply a zero tax on reproducible factors $\mathrm{K}$ and $\mathrm{H}$ in every period and a 100 percent tax in every period on the rents appropriated by the fixed factor. In fact, in the presence of such a fixed factor, private and social returns would be equal for the reproducible factors if the fixed factor is assumed to appropriate the rents; while the fixed factor would have a zero social return and a positive private return. Then, again, optimal taxation principles would require a full (in this case lumpsum) taxation of the returns to this fixed factor. Such solution would be again first best and lead a balanced budget in every period. If we could not tax the fixed factor separately from the taxation of the income of reproducible factors as in the case of an income tax, the optimal tax plan would correspond to that described in section 3.3 .1 below where we assume income taxes and consider a case where human capital is a non-reproducible asset. The above discussion
} 
While the above proposition suggests that Pigouvian taxes are sufficient to correct the external effect created by productive public spending, the proposition below shows that the corresponding menu of tax instruments is sufficiently large to make public debt or asset redundant, i.e. the solution to the optimal taxation problem does not require a Ramsey-type accumulation of public assets.

Proposition 3. In models 1 and 2, if government spending and tax rates are optimally chosen, the budget is instantaneously balanced both along the balanced-growth path and during the transition towards it. The optimal public debt is zero.

Proof: See Appendix B.

It should also be emphasized that, regardless of the presence of accumulated capital, once the government has chosen the optimally tax rates on human and physical capital income, it has no incentive to resort to a "surprise" taxation along an optimal path. We stress this point with the following remark.

Remark 1. The optimal policy is time-consistent.

Note that a comprehensive set of tax instruments for the government should also include taxes on the use of physical and human capital in the human capital accumulation sector as well as in the home production sector. In this section, all these tax rates are assumed to be equal to zero, but this restriction has no consequence when the spending-induced externality is exclusively in the production sector.

\subsection{Restrictions on available tax rates: income taxes}

Suppose that the set of available tax rates in the production sectors only includes an income tax, so that $\tau_{t}^{H}=\tau_{t}^{K}=\tau_{t}$. In general, there will be no tax policy that would support a first best allocation either in the short run or in the long run, because a unique tax rate cannot correct the externality-induced distortions. Rather than characterizing the second best solution for the general case, we will focus on two sub-cases that have been widely analyzed in the literature. One is a two-sector model without home production $(\eta=0)$ where capital is not an

therefore suggests that the introduction of a fixed factor in the model would not change any of the qualitative results of our analysis. 
input in the human capital accumulation factor $(\beta=0)$. A similar model without endogenous spending has been used by Lucas $[1988,1990]$ among others. The other model has neither home production nor accumulation of human capital, as in Barro [1990] and Barro and Sala-i-Martin [1992]. Differently from previous contributions, we show that, in these particular models, the optimal tax and financial plan allows the economy to grow at the first best rate (at least) in the long run. These examples are interesting because they highlights the non-redundancy of public debt and assets arising from restrictions on the set of available policy instruments.

\subsubsection{A one-sector model with productive government spending}

The next two propositions summarize our results for a modified version of Barro [1990].

Assumption 1 Assume that $B=0$ (there is no human capital accumulation sector) and $\eta=0$ (there is no labor-leisure choice). To guarantee a positive long-run balanced-growth rate, the production function has to be constant returns to scale in the reproducible factors. Thus, (2.1) is replaced with

$$
Y_{t}=A \bar{H}^{1-\alpha \epsilon} K_{t}^{\alpha \epsilon} G_{t}^{1-\alpha \epsilon}
$$

Proposition 4. When the government spending exerts an external effect on human capital (model 2), the optimal policy consists of a finite period of high taxation, after which the income tax is permanently set equal to zero. The long-run growth rate of the economy is the same as in a first-best allocation.

Proof See Appendix C.

A formal proof of the optimality of a zero long-run income tax can be derived by using the same methodology as in Appendix B. A richer proof, sheding light on the dynamic properties of the tax rate, is provided in Appendix C. In this appendix, we follow an alternative approach to the restricted planner problem, as discussed in Judd [1995b].

Clearly, the optimal tax policy cannot be attained without allowing for intertemporal borrowing and lending. It does not hold, for instance, if the policy 
maker has to follow a balanced budget rule. ${ }^{15}$ An important property of a longrun optimal income tax equal to zero is that the government finances its spending through the return on its assets. The optimal plan prescribes the accumulation of public assets in the short run, up to the point in which they are sufficient to finance government spending. ${ }^{16}$ It is useful to recall that the spending-to-output ratio is optimally chosen independently of the set of available tax instruments.

If the income tax rate was unrestricted, the accumulation of net public asset could be achieved through an initial wealth tax (capital levy). Since the initial capital is in fixed supply, the initial wealth tax is effectively a lump-sum tax. In the presence of restrictions imposing an upper limit to the tax rate on income, the optimal solution consists of setting the income tax at its maximum feasible rate over a finite time span, and then drop it to zero. The optimality of a bang-bang solution derives from a different supply elasticity of capital already in place (a tax on which is effectively lump-sum) and future investment. The initial period of high taxation generates large primary surpluses that build the net asset position for the government.

The optimality of a positive net asset position for the government is a quite general result (see Corsetti [1992]). However, the result of a long-run income tax equal to zero in the one-sector model depends on the human capital being inelastically supplied. It will not characterize, in general, the second-best solution for the one-sector model with an elastic labor supply, let alone the three-sector model that we have discussed in the previous sections.

\footnotetext{
${ }^{15}$ Barro [1990] and Barro and Sala-i-Martin [1992, 1995] elaborate on the issue of the relative welfare properties of lump-sum and income taxation in models without public borrowing and lending. In particular, they stress the link between optimal taxation and the nature of public goods included in the analysis. For instance, in the presence of congestion in the use of the public good, an optimal policy would require the use of a proportional output tax. Relative to these studies, we introduce the possibility of borrowing and lending, we consider which is the factor (labor or capital) that receives the rents generated by the existence of public spendingrelated externalities and we distinguish between government spending externalities in the final goods sector and in the human capital accumulation sector. The optimal taxation results that we obtain are therefore substantially different from those in Barro [1990] and Barro and Salai-Martin [1992, 1995]; in particular, we show that first best allocations can be obtained if the optimal plan includes enough policy instruments. In this regard, the existence of public borrowing and/or lending becomes crucial in order to achieve first best growth rates and factor allocations.

${ }^{16}$ Corsetti [1992] derives these results addressing the problem from the standpoint of portfolio allocation.
} 
It is worth stressing that, as long as the upper limit on the tax rate cannot be violated, the optimal policy is time-consistent. Once the optimal policy is in place, there is no incentive for the government to deviate from it at any point in time. In the long run, an optimal level of spending is financed exclusively with income from financial and/or real assets. There is no need to resort to a surprise income taxation. In the short run, as long as lump-sum wealth taxation is ruled out, the optimal tax rate is already set to its maximum possible value. Therefore, by construction, the government cannot surprise agents by raising tax rates (of course there is no incentive for a tax cut). ${ }^{17}$

Conversely, suboptimal policies are time inconsistent. This insight is exploited by Benhabib and Velasco [1995], that use the Barro [1990] model to explore the economics of fiscal populism in an open economy. They assume distortionary taxation on output and impose a balanced budget rule that prevent the policy maker to run an optimal tax program. Because of "populism", i.e. the temptation for a benevolent policy maker to resort to higher taxation and spending when capital is already in place, the economy suffer from under-accumulation. Clearly, allowing for the possibility of public borrowing and lending rules out this possibility.

We consider next the optimal policy when the spending-related externalities are on physical capital.

Proposition 5. When government spending exerts an external effect on physical capital (model 1), the optimal long-run income tax is positive and equal to $\tau_{t}=$ $(1-\epsilon)$. Provided that the government can make positive transfers to the private sector, such a policy supports a first-best allocation.

The result yet again depends on human capital being inelastically supplied. As capital income should be taxed to the extent of the externality, an income tax can achieve this objective without distorting the labor (or human capital accumulation) decision $-\mathrm{H}$ is in fixed supply. Nonetheless, the income tax rate required to correct the price of capital is too large relative to spending. The government runs a primary (non-interest) surplus. The primary surplus can be redistributed in a non distortionary way to household either by using lump-sum transfers over time, or by resorting to an initial distribution of government bonds.

\footnotetext{
${ }^{17}$ Sargent [1987] discusses the time consistenty of an optimal dynamic taxation problem. It concludes that the optimal solution is time-inconsistent if the policy-maker can bypass - if only instantaneously - the initial restrictions on tax rates. Clearly, the underlying specification of the model is different from ours, in that upper limits on tax rates can be ignored by the policy maker at any point in time but the initial period.
} 
Then the optimal tax is always equal to $(1-\epsilon)$, and the optimal plan supports a first-best allocation both in the short run and the long run. ${ }^{18}$

It should be stressed that, regardless of the presence of a positive stock of public debt in the long run, the optimal solution is again time consistent. The existence of public liabilities creates no incentive for a welfare-improving taxhike or capital levy. These policies would be welfare-improving if taxes were effectively distortionary, so that a positive debt would reduce economic efficiency via the excess burden of taxation. However, in the specification we are focusing on, tax rates (although non lump-sum) are not distortionary, since they correct an externality. Then the function of public debt is to redistribute excess public revenue in a lump-sum fashion.

\subsubsection{A two-sector model with productive spending}

In this section we discuss optimal financial policies with income taxes in a twosector version of our model. The underlying change in our specification is the following.

Assumption Assume that $\beta=0$ (physical capital is not an input in the human capital accumulation sector) and $\eta=0$ (there is no labor-leisure choice).

The model is identical to Lucas $[1988,1990]$ but for the role of public spending in production. Quite interestingly, we are able to derive two propositions that are quite close to those characterizing the "Barro" type of model in the previous section. We state these result without presenting a formal proof. ${ }^{19}$

Proposition 6. When government spending exerts an external effect on human capital (model 2), the optimal long run income tax is zero $\tau_{\infty}=0$. The corresponding long-run growth rate and capital ratios are the same as in a first-best allocation.

\footnotetext{
${ }^{18}$ If lump-sum transfers (also in the form of an initial distribution of bonds) are ruled out, the optimal plan is involves an initial period of deficit spending, during which the government builds up the optimal stock of public debt. In the long run, the tax rate becomes positive, generating a primary surplus that is redistributed in the form of interest on government liabilities. The long-run growth rate is again equivalent to the first best one.

${ }^{19} \mathrm{~A}$ formal proof can be derived by applying the same methodology presented in Appendix I and is available upon request.
} 
Proposition 7. When government spending exerts an effect on physical capital (model 1), the optimal long-run income tax is positive and equal to $\tau_{t}=(1-\epsilon){ }^{20}$

Why is the optimal taxation and spending policy very similar in a Lucas-type model with productive spending and in a Barro-type model? The key common characteristic of the two models is that a tax rate on income from human capital has no effects on long-run growth, factor allocation and consumption. In a "Barro model", such result derives from the assumptions that human capital is fixed (not accumulable) and that there is no labor-leisure choice. In the "Lucas model", human capital can be accumulated. Nevertheless, in the absence of a labor-leisure choice, a tax on human capital income reduces the costs and the return to human capital accumulation by the same amount. Hence, in the long run, household allocation decisions about human capital accumulation are independent of tax rates (see Milesi-Ferretti and Roubini [1994a,1995] for a detailed discussion of this point).

Since in the "Lucas model" any tax on human capital is effectively lump sum, the intuition behind the above propositions is the same as in the case of the "Barro model". If the spending-related rents go to physical capital, the goal of a positive income tax rate is to correct the externality. An optimal allocation can be implemented thanks to the fact that the income tax has no effect on human capital allocation or accumulation. Conversely, when the spending-related rents go to human capital, these have no external effect on human capital-related decisions, i.e. rents do not alter household behavior. Then, a positive income tax is neither needed nor desirable, since it would not correct private decisions regarding human capital accumulation or allocation, but it would distort the return on physical capital. Thus, an optimal policy consists of setting long-run income taxes to zero, while accumulating assets in the short-run vis-á-vis the government financial requirements.

\footnotetext{
${ }^{20}$ As in the corresponding proposition for the one sector model, the optimal policy supports the first-best allocation both in the short and the long run when the policy maker can redistribute the primary surplus back to households in a non distortionary fashion. Otherwise, the optimal plan can achieve the same growth rate and capital ratios as in the first-best allocation only in the long-run where there is a positive stock of public debt.
} 


\section{Public good as an input in the human capital accumula- tion sector}

We finally consider the nature of optimal spending and tax policy when public spending affects the productivity of the human capital accumulation sector. So far, we have assumed that the human capital accumulation sector is a non-market sector in which factor incomes are non-taxed. Obviously this is a modeling assumption that can be easily relaxed. ${ }^{21}$

To understand the nature of optimal policies, consider first what would happen if the factors in the human accumulation sectors could be taxed. In the most general case, we could assume the existence of four tax instruments: two different tax rates on the human capital income, one for each sector, and two different tax rates on the physical capital income, one for each sector. ${ }^{22}$ If such a set of tax instruments were available, the optimal tax policy would be symmetric to the one derived in the previous sections, where $G$ was assumed to affect the productivity of the final goods sector only. Specifically, the tax on physical capital income would be zero (positive) while the tax on human capital income would be positive (zero) if government spending affects the productivity of human (physical) capital.

Starting from this paradigm, we can now consider the effects of various restrictions on tax instruments. Suppose we can tax the factors in the human capital sector only through a common tax (a tax on the income of the human capital sector). While such a restriction allowed to replicate the first best growth rate and factor allocations in some variants of the model of the previous sections (see the Lucas and Barro cases), it will now make it impossible to replicate a first best equilibrium. For instance, consider a Lucas-type model with government spending entering as an input in the $\mathrm{H}$ sector only. Even if physical capital does not affect the production of $\mathrm{H}$ directly, the rate of human capital accumulation along the balanced-growth path will nonetheless depend on capital through the shadow price of physical resources used up in government consumption. The optimal spending and tax plan with income taxes in the $\mathrm{H}$ sector will be only a second best, since the number of tax and fiscal instruments available is not sufficient to

\footnotetext{
${ }^{21}$ For example, Pecorino [1993], Stokey and Rebelo [1995] and Milesi-Ferretti and Roubini [1995] consider the effects of taxes on growth when the human capital sector is assumed to be a market sector where returns are taxable.

${ }^{22}$ Clearly, taxation of factor inputs in the human capital accumulation sector requires the computation of the price of human capital relative to physical capital. For simplicitly, we could assume that the human capital accumulation sector is a market sector, so that this relative price is just a market price.
} 
correct the distortions generated by government spending without, at the same time, distorting the allocation choices in the final goods production sector.

As another restriction on the menu of tax instruments, we could constrain the policy maker to tax human capital income at the same rate in both sectors; by the same token, physical capital income could only be taxed at the same rate in both sectors. Again, even in the presence of government borrowing and lending, such a set of restrictions would not allow the policy maker to replicate the first best growth rate and factor allocations, either in the short run or the long run. Any use of either tax to correct the externality in the education sector would also affect factor allocations in the final goods sector. So the optimal restricted spending and tax plan would be necessarily second best.

Finally, if we assume that the imputed income to the factors of production in the human capital accumulation sector cannot be taxed, there is no way that tax policy could completely correct the externalities in that sector. Any use of the available taxes (on the income to human and physical capital in the final goods sector) would distort the allocation decisions and will not correct the externalities present in the education sector. Again, in this case the optimal restricted policy plan would be second best.

This point can be illustrated in reference to the analysis by Jones Manuelli and Rossi [1993] (hereafter JMR), who address the issue of a joint characterization of spending and tax rates in a two-sector model where production requires only physical capital, but investment requires both output and public goods in ways similar to our models in which spending affects the productivity of the human capital accumulation sector.

The specification by JMR entails the existence of pure profits in the capital accumulation sector. This implies the optimality of lump-sum taxes that can endow the public sector with a claim on private output as large as the pure profits in the capital accumulation sector. An initial capital levy is therefore efficient. If the initial capital taxation is subject to a binding upper limit, JMR show that the efficient limiting tax on capital income does not go to zero. In order to understand this point, consider that, similarly to the case of our model 3 and 4 , the government can choose the size of spending but has no direct instrument to correct the spending-induced distortions in the second sector: it can only affect investment through its choice of capital taxes. ${ }^{23}$ As the incentive to invest is

23"The planner has full control over $G$, but can influence the [investment decision] only indirectly through the choice of capital tax rates. This is the reason why limiting tax rates are positive" Jones, Manuelli and Rossi [1993], p. 507. 
too high, because of the pure profits in the sector, in a second best world, the long run optimal solution has a small positive capital income tax that indirectly "discourage" investment, while government spending is also set at a suboptimally low level.

\section{Concluding remarks}

The recent literature on taxation and growth has stressed the optimality of a zero long-run taxation on all accumulable factors of production. For a given path of government spending, the optimal tax plan requires the government to build up a positive stock of public wealth in the short run; in the long-run, government spending can be financed with the income accruing from the management of the portfolio of public assets, rather than resorting to distortionary taxation.

The optimality of creditor states is a typical result in Ramsey-type analyses of optimal taxation problems. In the unconstrained version of the problem, the government can build-up assets in an efficient way through an initial capital levy (wealth tax). Even when the initial tax rates are constrained so as to rule out the most efficient initial period wealth tax, it would be still optimal to build up asset as fast as possible in the short run. Tax rates on the income from accumulable factors should be set at their maximum value, then dropped to zero in the longrun. The initial period of high taxation coincides with the accumulation of public wealth. Clearly, the allocation will only be second-best.

In this paper, we have analyzed the characteristics of the optimal policy in models where government spending is endogenous. In particular, we have focused on three sector endogenous growth models with productive spending, under different assumptions on a) which sector of the economy benefits from the supply of productive public goods by the government and b) which factor of production benefits from the external effects of government spending on productivity.

First, we have shown that, when government spending is productive and the government can tax human and physical capital at different rates, the optimal tax and spending plan replicates the first best solution (command optimum) both in the short and the long run. The optimal tax plan clearly consists of taxing away, in both the short and long run, the externality-related rents, using as tax base the income of the specific factors that appropriate those rents. The public budget will be in balance in every period and no public debt or assets will be required to sustain the first best.

Second, we have analyzed optimal policy in the presence of restrictions to the 
menu of available tax instruments. A notable example is the case of an income tax (a common tax rate on physical and human capital income); another case is when the use of inputs in some specific sector (education) is not taxed. The result in our exercise of policy design is that, when the set of tax instruments is restricted, the optimal policy plan may require the use of borrowing and/or lending to smooth distortions over time. In general, the ability to borrow and lend will not be a perfect substitute for the lack of sufficient tax instruments; the restricted optimal plan will then be second best. We have characterized second-best policies involving intertemporal smoothing of distortions within the framework of Barro's model of spending and growth, and a modified version of the Lucas model, including productive government spending.

Note that our first set of results points out an apparent (yet only superficial) difference between the optimal policy in our model and the traditional Ramsey solution that applies to similar models without externalities and public goods (i.e. to models in which government spending is non productive and follows some exogenously given path). In such models, the possibility of charging different tax rates on income from human capital and physical capital is not sufficient to guarantee first-best policies(see Milesi-Ferretti and Roubini [1995] for a discussion of a model that is similar to the one presented in the text).

Conversely, the second set of results suggests an important analogy between the second best policies in our model and the dynamic optimal taxation drawing on Ramsey, as developed by Chamley[1986] and Judd[1985]. The analogy is best understood by pointing out that the second-best optimal taxation plans in Chamley is derived under a set of restrictions on the menu of available tax instruments that rule out consumption and wealth taxes. In the presence of such restrictions, intertemporal borrowing and lending becomes the additional policy tool that allows the implementation of welfare-improving tax and financial policies. In our paper, we have studied the design of optimal policies with endogenous spending by following the same logical steps. First, we have identified a set of tax instruments that support the first-best allocation. Then, we have constrained this set, and derive results proving the non-redundancy of intertemporal borrowing and lending. 


\section{- Appendix A}

In this appendix we first describe the firm level technologies that correspond to the rates of return included in Table 2 ; next, we describe in detail the competitive equilibrium of the model.

As regards the first issue, we specify the set of technologies that private agents face in a market (decentralized) economy and that are consistent with the aggregate production functions (2.1) and (2.3). We focus on technologies that, from standpoint of firms and households, are constant returns to scale to private inputs, so that, in a competitive equilibrium, the value of the privately produced output is exhausted by the payments to human and physical capital (excluding fixed factors of production). As mentioned in the main text, for the sake of simplicity we will analyze market allocations in which the external effect of government spending raises the productivity of only one factor of production, so that spending-related production rents go to either human capital or physical capital.

Consider first the case in which $\mathrm{G}$ is an input in the production of final output $(\mathrm{Y})$. If $\mathrm{G}$ increases the productivity of human capital, individual firms will face a production function of the following form:

$$
Y_{i}=A\left[\left(v_{i} K\right)\right]^{\alpha \epsilon}\left[\left(u_{i} \widetilde{H}\right)\right]^{1-\epsilon \alpha}
$$

where we measure the amount of inputs employed by the i-th firm as fractions of their total supply in the economy; consistently with (2.1), the effective human capital in the output sector $u \widetilde{H}$ is:

$$
u \widetilde{H}=\left[(u H)^{1-\alpha} G^{\alpha(1-\epsilon)}\right]^{\frac{1}{1-\epsilon \alpha}}
$$

The economic intuition of this expression is best understood by noticing that the effective capital in the output sector is constant returns to scale in $u H$ and $G$. Note that, positing $\epsilon=0$, i.e. the model becomes a two-sector version of Barro [1990], whereas the accumulable input in the output sector is human rather than physical capital.

Analogously, if $\mathrm{G}$ increases the productivity of physical capital, the individual firm production function will be:

$$
Y_{i}=A\left[\left(v_{i} \widetilde{K}\right)\right]^{\alpha}\left[\left(u_{i} H\right)\right]^{1-\alpha}
$$

where $v \widetilde{K}$ is the effective physical capital in the output sector:

$$
v \widetilde{K}=\left[(v K)^{\epsilon \alpha} G^{\alpha(1-\epsilon)}\right]^{\frac{1}{\alpha}}
$$


It is worth stressing that, at the aggregate level, both (A.1) and (A.3) lead to the same social production function (2.1).

As regards the case in which government spending affects the productivity of the human capital accumulation sector, the technology faced by individual agents and institutions in models 3 and 4 can be derived in the same way as in (A.1) through (A.4). In this paper, we assume that the education sector where human capital is produced is non-market, and that the returns to the factors employed in this sector are not subject to factor income taxation (see also Milesi-Ferretti and Roubini (1995) for a detailed discussion).

Regardless of the nature of the spending-related externalities and their implications for distribution, the formal solution to the consumer problem is identical in our four specifications. The representative consumer takes the path of $G, \tau^{K}$ and $\tau^{H}$ as given, and chooses the paths of $C, B, K, H, u, v, x$ and $z$ which maximize her utility subject to the relevant constraints. The first order conditions for the consumer problem are as follows:

$$
\begin{gathered}
e^{-\rho t} C_{t}^{-\theta} L_{t}^{\eta(1-\theta)}=\lambda_{t} \\
-\frac{\dot{\lambda}_{t}}{\lambda_{t}}=R_{t}^{K}\left(1-\tau_{t}^{K}\right)-\delta=r_{t} \\
-\frac{\dot{\mu}_{t}}{\mu_{t}}=\rho_{t}^{H}-\delta \\
R_{t}^{K}\left(1-\tau_{t}^{K}\right)=\frac{\gamma \eta C_{t}}{\left(1-v_{t}-x_{t}\right) K_{t}} \\
R_{t}^{H}\left(1-\tau_{t}^{H}\right)=\frac{(1-\gamma) \eta C_{t}}{\left(1-u_{t}-z_{t}\right) H_{t}} \\
\frac{R_{t}^{K}\left(1-\tau_{t}^{K}\right)}{R_{t}^{H}\left(1-\tau_{t}^{H}\right)}=\frac{\rho_{t}^{K}}{\rho_{t}^{H}} \\
\frac{R_{t}^{K}\left(1-\tau_{t}^{K}\right)}{R_{t}^{H}\left(1-\tau_{t}^{H}\right)}=\frac{h_{t}^{K}}{h_{t}^{H}} \frac{\gamma}{1-\gamma}
\end{gathered}
$$

where $h^{K}$ and $h^{H}$ relate returns to physical and human capital in the home production sector to the marginal utility of home goods. $h^{K}$ and $h^{H}$ are defined as 
follows

$$
\begin{gathered}
h_{t}^{K} \equiv\left[\frac{\left(1-v_{t}-x_{t}\right) K_{t}}{\left(1-u_{t}-z_{t}\right) H_{t}}\right]^{\eta \gamma(1-\theta)-1}\left[\left(1-u_{t}-z_{t}\right) H\right]^{\eta(1-\theta)-1} \\
h_{t}^{H} \equiv\left[\frac{\left(1-v_{t}-x_{t}\right) K_{t}}{\left(1-u_{t}-z_{t}\right) H_{t}}\right] h_{t}^{K}
\end{gathered}
$$

Equation (A.5) states that the shadow price of consumption (physical capital) must be equal to the marginal utility of consumption in every period. Equation (A.6) is the first order condition for capital accumulation: the rate of change of the shadow value of consumption must be equal to the marginal product of capital net of tax, which must also be equal to the rate of return on government bonds. Equation (A.7) is the corresponding first order condition for human capital accumulation, relating the change in the shadow price of human capital to its marginal return. Equations (A.8) to (A.11) derive from the first order conditions for the optimal allocation of the factors in the three sectors.

Finally, the remaining conditions are the constraints (2.8) and (2.3), and the transversality conditions

$$
\begin{aligned}
& \lim _{t \rightarrow \infty} \lambda_{t} K_{t}=0 \\
& \lim _{t \rightarrow \infty} \mu_{t} H_{t}=0
\end{aligned}
$$

The balanced-growth rate of the economy shown in the text is obtained by log-differentiating (A.5) and using the fact that, along the balanced-growth path, factor allocation parameters are constant.

Along such path, the shadow prices of physical and human capital must decline at the same rate. By equating the corresponding expressions (A.6) and (A.7), we get the following condition characterizing the balanced-growth path

$$
R^{K}\left(1-\tau^{K}\right)=\rho^{H}
$$




\section{- Appendix B}

The goal of this appendix is to derive the set of optimal policies described in the text as solutions to the restricted planner problems. For model 1 and 2, the restricted planner problem can be written as follows

$$
\underset{\{C, K, H, G, v, x, u, x\}}{\operatorname{Max}} \int_{0}^{\infty} W_{t}-\Psi \widehat{W}_{0}
$$

where

$$
W_{t} \equiv(1+\psi) \int_{s=t}^{\infty} e^{-\rho s}\left(C_{s} L_{s}^{\eta}\right)^{1-\theta} d s
$$

and

$$
\int_{0}^{\infty} e^{-\rho t}\left(C_{t} L_{t}^{\eta}\right)^{1-\theta}=\widehat{W}_{0}
$$

The latter expression is an "implementability constraints", stating that the present discounted value of consumption - including market goods and home production - must be equal to the consumer's total wealth ( $\Psi$ is the associated Lagrange multiplier) (See Milesi-Ferretti and Roubini [1994] for details). The maximization problem is further subject to the two resources constraints for physical and human capital:

$$
\begin{gathered}
\dot{K}_{t}=A_{t}\left(v_{t} K_{t}\right)^{\epsilon \alpha}\left(u_{t} H_{t}\right)^{1-\alpha} G_{t}^{\alpha(1-\epsilon)}-G_{t}-C_{t}-\delta K_{t} \\
\dot{H}_{t}=B\left(x_{t} K_{t}\right)^{\beta}\left(z_{t} H_{t}\right)^{1-\beta}-\delta H_{t}
\end{gathered}
$$

and the set of market allocation constraints

$$
\begin{gathered}
\int_{t=0}^{t} \frac{C_{s}}{\left(1-v_{s}-x_{s}\right) K_{s}} d s= \\
\frac{1}{\gamma \eta}\left[\theta \log C_{t}-\eta(1-\theta) \log L_{t}-\theta \log C_{0}+\eta(1-\theta) \log L_{0}+(\delta+\rho) t\right] \\
\frac{1-\beta}{\beta} \frac{\gamma}{1-\gamma}=\frac{1-v_{t}-x_{t}}{x_{t}} \frac{z_{t}}{1-u_{t}-z_{t}} \\
(1+\psi)\left(C_{t} L_{t}^{\eta}\right)^{1-\theta}=F_{t}(1+\psi) \int_{s=t}^{\infty} e^{-\rho s}\left(C_{s} L_{s}^{\eta}\right)^{1-\theta} Q_{s} d s
\end{gathered}
$$


where

$$
F_{t} \equiv\left(1-u_{t}-z_{t}\right) B\left(\frac{x_{t} K_{t}}{z_{t} H_{t}}\right)^{\beta}
$$

and

$$
Q_{s} \equiv \frac{1-z_{s}-\beta}{1-u_{s}-z_{s}}
$$

The market allocation constraints are derived from the first order conditions of the consumer problem in section 2.5 and the relevant budget constraints.

Denote with $\lambda, \mu, \varphi, \xi, \phi$ the multipliers associated with (B.2) through (B.6). Dropping the time subscript for notational thrift, the first order conditions for this problem are

$$
\begin{aligned}
& W_{C}[1+\phi(1-F Q)]-\lambda+\varphi\left[\frac{1}{(1-v-x) K}-\frac{\theta}{\gamma \eta C}\right] \\
& -\dot{\lambda}=W_{K}[1+\phi(1-F Q)]+\lambda\left[\epsilon \alpha K^{-1} Y-\delta\right]+ \\
& \mu \beta B x\left(\frac{x K}{z H}\right)^{\beta-1}-\beta K^{-1} \phi W-\varphi K^{-1}\left[\frac{C}{(1-v-x) K}-(1-\theta)\right] \\
& -\dot{\mu}=W_{H}[1+\phi(1-F Q)]+\lambda\left[(1-\alpha) H^{-1} Y\right]+ \\
& \mu\left[(1-\beta) B z\left(\frac{x K}{z H}\right)^{\beta}-\delta\right]+\beta H^{-1} \phi W+\varphi H^{-1} \frac{\gamma(1-\theta)}{1-\gamma} \\
& G=\alpha(1-\epsilon) Y \\
& W_{v}[1+\phi(1-F Q)]+\lambda \epsilon \alpha v^{-1} Y-\frac{\xi}{x}+ \\
& \frac{\varphi}{1-v-x}\left[\frac{C}{(1-v-x) K}-(1-\theta)\right]=0 \\
& W_{u}[1+\phi(1-F Q)]+\lambda(1-\alpha) u^{-1} Y- \\
& \frac{\xi}{z} \frac{1-\beta}{\beta} \frac{\gamma}{1-\gamma}-\frac{\varphi(1-\theta)}{1-u-z} \frac{1-\gamma}{\gamma}+\frac{\phi W(1-F Q)}{1-u-z}=0 \\
& W_{x}[1+\phi(1-F Q)]+\mu \beta B K\left(\frac{x K}{z H}\right)^{\beta-1}-\frac{\phi \beta W}{x}-
\end{aligned}
$$




$$
\begin{gathered}
\frac{\xi}{x} \frac{1-v}{x}+\frac{\varphi}{1-v-x}\left[\frac{C}{(1-v-x) K}-(1-\theta)\right]=0 \\
W_{z}[1+\phi(1-F Q)]+\mu(1-\beta) B K\left(\frac{x K}{z H}\right)^{\beta}+\frac{\xi}{z} \frac{1-\beta}{\beta} \frac{\gamma}{1-\gamma} \frac{1-v}{z}- \\
\frac{\varphi(1-\theta)}{1-u-z} \frac{1-\gamma}{\gamma}+\frac{\phi W}{1-u-z}\left[1+\frac{\beta(1-u-z)}{z}-\frac{u-\beta}{1-\beta-z} F Q\right]=0
\end{gathered}
$$

The proof of the propositions in the text goes as follows. First, the optimal spending rate is always equal to $\alpha(1-\epsilon) Y_{t}$, independently of whether or not the policy maker is pursuing an optimal financing policy, as well as of whether or not the economy is in a long run balanced-growth path. Second, given that $W_{x}=W_{v}$ combining (B.13), (B.15) and (B.10), we obtain

$$
-\frac{\dot{\lambda}}{\lambda}=\left[\epsilon \alpha A\left(\frac{v K}{u H}\right)^{\alpha-1}\left(\frac{G}{v K}\right)^{\alpha(1-\epsilon)}-\delta\right]
$$

Comparing this expression with those of the consumer problem (A.6), it is immediate to verify that a benevolent policy maker will optimally set the tax on capital equal to zero in model 1 , and equal to $(1-\epsilon)$ in model 2. Next, we show that, when the policy maker pursues the optimal policy, the multipliers associated with the market equilibrium are all equal to zero, $\varphi=\xi=\phi=0$. Using (B.9), (B.13) and the fact that $W_{c}=-\frac{1-v-x}{\gamma \eta C}$, we obtain

$$
\begin{gathered}
\lambda\left[\frac{\eta \gamma C}{1-v-x}-\epsilon \alpha A\left(\frac{v K}{u H}\right)^{\alpha-1}\left(\frac{G}{v K}\right)^{\alpha(1-\epsilon)}\right]= \\
-\frac{\xi}{x}+\frac{\varphi}{1-v-x}\left[\frac{C(1+\eta \gamma)}{(1-v-x) K}-1\right]
\end{gathered}
$$

Provided that the policy maker pursues an optimal tax policy, by the market equilibrium condition

$$
\frac{\eta \gamma C}{1-v-x}-R^{K}\left(1-\tau^{K}\right)=0
$$

we know that the left hand side of (B.17) is equal to zero. Moreover, by using (B.14), (B.16) and (B.11), combined with the fact that $W_{u}=-W_{H} \frac{H}{1-u-z}$, we obtain

$$
-\frac{\dot{\mu}}{\mu}-\left[(1-\beta) B\left(\frac{x K}{z H}\right)^{\beta}-\delta\right]=
$$




$$
\frac{\phi W}{z}\left[\frac{\beta}{z}+1+\frac{F Q \beta}{1-\beta-z}\right]+\frac{\xi}{H} \frac{1-\beta}{\beta} \frac{\gamma}{1-\gamma} \frac{1-v-z}{z^{2}}
$$

By the market equilibrium condition

$$
-\frac{\dot{\mu}}{\mu}=\rho^{H}-\delta=(1-\beta) B\left(\frac{x K}{z H}\right)^{\beta}-\delta
$$

the left hand side of (B.18) is also equal to zero. Thus, for both (B.17) and (B.18) to hold with an optimal policy in place, the three multipliers $\varphi, \xi$ and $\phi$ associated with the market allocation conditions must all be equal to zero. As a final step of the proof, we complete the characterization of the optimal policy by identifying the optimal tax on human capital. Using (B.9) and (B.14), we write

$$
\begin{gathered}
\lambda\left[\frac{\eta(1-\gamma) C}{1-u-z}-(1-\alpha) H A\left(\frac{v K}{u H}\right)^{\alpha}\left(\frac{G}{v K}\right)^{\alpha(1-\epsilon)}\right]= \\
=\frac{\xi}{z} \frac{1-\beta}{\beta} \frac{\gamma}{1-\gamma}+\frac{\varphi}{1-u-z}\left[\frac{\eta(1-\gamma) C}{1-v-x}-\frac{1-\gamma}{\gamma}\right]+\frac{\phi W(1-F Q)}{1-u-z}
\end{gathered}
$$

The right hand side of this expression is zero when the three multipliers $\varphi, \xi$ and $\phi$ are all equal to zero. For condition (B.19) to hold, by the first order condition of the consumer problem

$$
\frac{\eta(1-\gamma) C}{1-u-z}-R^{H}\left(1-\tau^{H}\right) H=0
$$

the policy maker must be set $\tau^{H}=0$ in model 1 , and $\tau^{H}=\frac{\alpha(1-\epsilon)}{1-\epsilon \alpha}$ in model 2. We can now verify that implementing an optimal policy implies a balanced budget and a zero stock of public debt

$$
\tau^{K} v K R^{K}=(1-\epsilon) \alpha Y=G
$$

for model 1 and

$$
\tau^{H} v K R^{H}=(1-\epsilon) \alpha Y=G
$$

for model 2 . 


\section{- Appendix C}

In this appendix, we provide a proof for the optimal taxation and spending plan in a Barro-type economy following a different methodology relative to Appendix B. This methodology is thoroughly analyzed in Judd[1995]. We refer to this paper for details as well for a discussion of the proof in the general case.

Consider first the market allocation. Omitting the time subscript, the first order condition for the representative consumer problem are

$$
\begin{gathered}
C^{-\theta}=\lambda \\
\dot{\lambda}=\lambda(\rho-\bar{r})
\end{gathered}
$$

where $\bar{r}$ is the rate of interest net of income taxes and $\lambda$ is the multiplier associated with the private budget constraint. Differently from Appendix B, we use a present value Hamiltonian.

Relative to the problem addressed in Appendix B, we note that, with an inelastic supply of human capital, an income tax has no distortionary effects on human capital accumulation decisions. However, we now consider a flat tax on income, rather than differential tax rates on factor income. As human capital is in fixed supply, it is convenient to write the after-tax income on human capital $\bar{w} \bar{H}$ as a transformation of the income on physical capital $\bar{r}$

$$
\bar{w} \bar{H}=\bar{r} \frac{1-\alpha \epsilon}{\alpha \epsilon} K
$$

so that total net income can be written as follows:

$$
Y(1-\tau)=(1-\tau)[r K+w \bar{H}]=\bar{r} \frac{K}{\alpha \epsilon}
$$

The restricted social planner problem consists of choosing C, G and the aftertax interest rate $(\bar{r})$ that maximize the representative consumer utility subject to the resource constraint, the public sector budget constraint, the first order conditions for the market allocation and a constraint on the maximum tax rate, assumed to be $100 \%$. The latter condition can be expressed as a non-negativity constraint on the after-tax return on capital, that is $\bar{r} \geq 0$. This problem is represented by the following Hamiltonian

$$
\mathbb{H}=\frac{C^{1-\theta}}{1-\theta}+\phi_{K}\left[A K^{\alpha \epsilon}(\bar{H} G)^{1-\alpha \epsilon}-C-G-\delta K\right]+
$$




$$
\begin{aligned}
& \mu\left[\bar{r} B-\left(A K^{\alpha \epsilon}(\bar{H} G)^{1-\alpha \epsilon}-\bar{r} \frac{K}{\alpha \epsilon}-G\right)\right]+ \\
& \phi_{\lambda} \lambda(\rho-\bar{r})+\phi_{C}\left(C^{-\theta}-\lambda\right)+\nu \bar{r}
\end{aligned}
$$

where $\phi_{K}, \mu, \phi_{\lambda}$ are the multipliers associated with the state variables $\mathrm{K}, \mathrm{B}$ and $\lambda ; \phi_{C}$ is the social marginal value of the requirement that the consumption choice be consistent with individual intertemporal optimization, while $\nu$ is positive whenever the constraint on the maximum rate of income taxation is binding (that is, when, with a $100 \%$ maximum tax rate, the after-tax interest on capital is zero). It is worth stressing that the above Hamiltonian is linear in the control variable $\bar{r}$. Once we consider this feature of the problem together with the constraint on the tax rate, we know that the optimal policy will correspond to a bang-bang solution.

The first order conditions for the problem are

$$
\begin{gathered}
\mathbb{H}_{C}=C^{-\theta}-\phi_{K}-\phi_{C} \theta C^{-\theta-1}=0 \\
\mathbb{H}_{\bar{r}}=-\phi_{\lambda}+\mu\left(B+\frac{K}{\alpha \epsilon}\right)+\nu=0 \\
\mathbb{H}_{G}=\left(\phi_{K}-\mu\right)\left[(1-\alpha \epsilon) A K^{\alpha \epsilon} \bar{H}^{1-\alpha \epsilon} G^{-\alpha \epsilon}-1\right]=0
\end{gathered}
$$

The costate equations are

$$
\begin{gathered}
\dot{\phi}_{K}=\rho \phi_{K}-\phi_{K}\left[\alpha \epsilon A K^{\alpha \epsilon-1}(\bar{H} G)^{1-\alpha \epsilon}-\delta\right] \\
-\mu\left[\alpha \epsilon A K^{\alpha \epsilon-1}(\bar{H} G)^{1-\alpha \epsilon}-\frac{\bar{r}}{\alpha \epsilon}\right] \\
\dot{\mu}=\mu(\rho-\bar{r}) \\
\dot{\phi}_{\lambda}=\bar{r} \phi_{\lambda}+\phi_{C}
\end{gathered}
$$

In addition, as the value of $\lambda$ is free variable at the initial time, $\lambda(0)$ is optimally chosen by the planner:

$$
\mathbb{H}_{\lambda}(0)=0 \text { and } \phi_{\lambda}(0)=0
$$

implying that $\phi_{c}(0)=0$. Upon substitution in the first order condition $\mathbb{H}_{C}(0)=0$, it follows that $\lambda(0)=\phi_{K}(0)$.

The multiplier $\lambda$ is equal to private marginal utility, that is positive $(\lambda>0)$. The social marginal value of government debt is non-positive $(\mu \leq 0)$ under the (mild) assumption that the government can distribute a positive stock of bonds 
to agents in the form of an initial transfer. Thus, in general, the ratio between $\lambda$ and $\mu$ will be negative. Moreover, as both $\lambda$ and $\mu$ grow at the same rate over time (equal to $\rho-\bar{r}$ ) their ratio will be constant. We summarize these properties of the solution as follows

$$
m \equiv-\frac{\lambda}{\mu}>0 \text { and constant }
$$

As regards optimal spending, from $\mathbb{H}_{G}=0$ we can derive

$$
\frac{G}{Y}=1-\alpha \epsilon
$$

The difference between this expression and (3.1) in the text depends on the reparametrization of the production function in section 3.3.1.

We now characterize the dynamic properties of the optimal tax policy. By combining the costate equations with the first order conditions of the consumer problem, we obtain the following differential equation

$$
\frac{d}{d t} \frac{\phi_{K}-\mu}{\lambda}=\frac{\phi_{K}-\mu}{\lambda}\left[\bar{r}-\frac{\partial Y}{\partial K}\right]
$$

which has the general solution

$$
\frac{\phi_{K}-\mu}{\lambda}=\left(\frac{\phi_{K}(0)-\mu(0)}{\lambda(0)}\right) e^{\int^{t}\left(\bar{r}-\frac{\partial Y}{\partial K}\right) d s}
$$

Since, at $t=0, \lambda(0)=\phi_{K}(0)$, the ratio $\frac{\phi_{K}(0)-\mu(0)}{\lambda(0)}$ will be equal to $(1+m)$. We can therefore rewrite the above equation as

$$
\frac{\phi_{K}-\mu}{\lambda}=(1+m) e^{f^{t}\left(\bar{r}-\frac{\partial Y}{\partial K}\right) d s}>0
$$

The dynamic properties of the optimal income tax can be analyzed in terms of the evolution of $\frac{\phi K-\mu}{\lambda}$ under alternative assumptions on the constraint $\nu$.

When the constraint $\nu$ is binding, the tax rate is set at its maximum possible value. Assuming an upper bound income rate of $100 \%$, the after-tax return on capital is zero $(\bar{r}=0)$. In this case, the ratio $\frac{\phi_{K}-\mu}{\lambda}$ will decrease over time at a rate equal to the social return to capital $\left(\frac{\partial Y}{\partial K}\right)$. 
When the constraint $\nu$ is not binding, by combining the first order conditions of the problem with the costate equations, we obtain the following general relationship between multipliers and the curvature of the utility function

$$
\left(\frac{\phi_{K}-\mu}{\lambda}\right)=1-\frac{\mu}{\lambda}\left(\frac{C U_{C C}}{U_{C}}+1\right)
$$

Since in our model $\frac{C U_{C C}}{U_{C}}$ is always constant, it follows that, when the inequality constraint on tax rate is not binding, the ratio $\frac{\phi_{K}-\mu}{\lambda}$ is also constant:

$$
\left(\widehat{\frac{\phi_{K}-\mu}{\lambda}}\right)=1+m(1-\theta)
$$

Note that the value of $\frac{\phi_{K}-\mu}{\lambda}$ conditional on the inequality constraint being slack is clearly smaller than its initial value:

$$
\left(\widehat{\frac{\phi_{K}-\mu}{\lambda}}\right)=1+m(1-\theta)<\left(\frac{\phi_{K}(0)-\mu(0)}{\lambda(0)}\right)=1+m
$$

Thus, as soon as the constraint on the tax rate becomes slack, the ratio $\left(\frac{\phi_{K}-\mu}{\lambda}\right)$ stops decreasing and becomes a constant. At that point in time (denoted by T), the optimal income tax must be set equal to zero (so that the private and social marginal product of capital coincide)

$$
\begin{aligned}
& \widehat{\frac{\phi_{K}-\mu}{\lambda}}=(1+m) e^{\int^{T}\left(\bar{r}-\frac{\partial Y}{\partial K}\right) d s+\int_{T}^{\infty}\left(r-\frac{\partial Y}{\partial K}\right) d s}= \\
& (1+m) e^{\int^{T}\left(\bar{r}-\frac{\partial Y}{\partial K}\right) d s}
\end{aligned}
$$

The optimal tax policy has a bang-bang form: the income tax is set at $100 \%$ over a finite time interval $(0, T)$, then set to zero. 


\section{References}

[1] Arrow, Kenneth and Kurz, Mordechai [1970]. Public Investment, the Rate of Return and Optimal Fiscal Policy. Baltimore: Johns Hopkins University Press, 1970.

[2] Barro, Robert [1990], "Government Spending in a Simple Model of Endogenous Growth," Joumal of Political Economy 98, part 2, October, S103-S125.

[3] Barro, Robert and Xavier Sala-i-Martin [1992], "Public Finance in Models of Economic Growth," Review of Economic Studies 59, 645-661.

[4] Barro, Robert and Xavier Sala-i-Martin [1995], Economic Growth, McGraw Hill.

[5] Benhabib, Jess and Andres Velasco [1995]. "On the Economics of Fiscal Populism in an Open Economy," Institute for Empirical Macroeconomics Discussion Paper No.97, Federal Reserve Bank of Minneapolis, January.

[6] Benhabib, Jess, Richard Rogerson and Randall Wright [1991], "Homework in Macroeconomics: Household Production and Aggregate Fluctuations," Journal of Political Economy 99, December, 1166-1187.

[7] Chamley, Christophe [1986], "Optimal Taxation of Capital Income in General Equilibrium with Infinite Lives," Econometrica 54, May, 607-622.

[8] Chari, V.V., Lawrence Christiano and Patrick Kehoe [1994], "Optimal Fiscal Policy in a Business Cycle Model", Journal of Political Economy, 102(4), $617-652$.

[9] Corsetti, Giancarlo [1991], Uncertainty, Policy and Growth, unpublished Ph.D. dissertation, Yale University.

[10] Corsetti, Giancarlo [1995], "The Optimality of Creditor States: A Portfolio Perspective on Capital Taxation and Growth," mimeo, University of Rome.

[11] Corsetti, Giancarlo [1997], "A Portfolio Approach to Endogenous: Equilibrium and Optimal Policy" Journal of Economics Dynamics and Control, forthcoming. 
[12] Corsetti, Giancarlo and Nouriel Roubini [1996] "Tax Certificates as an Alternative to Distortionary Taxation," mimeo, New York University.

[13] Easterly, William and Sergio Rebelo [1994], "Fiscal Policy and Economic Growth: An Empirical Investigation,"CEPR Discussion Paper No.885, January.

[14] Glomm, Gerhard and B. Ravikumar [1994a] "Public Investment in Infrastructure in a Simple Growth Model," Journal of Economic Dynamics and Control.

[15] Glomm, Gerhard and B. Ravikumar [1994b] "Competitive Equilibrium and Public Investment Plans," mimeo, University of Virginia.

[16] Greenwood, Jeremy and Zvi Hercowitz [1991], "The Allocation of Capital and Time over the Business Cycle," Journal of Political Economy 99, December, $1188-1214$.

[17] Jones, Larry, Rodolfo E. Manuelli and Peter Rossi [1993], "Optimal Taxation in Models of Endogenous Growth," Journal of Political Economy 101, June, 485-517.

[18] Jones, Larry, Rodolfo E. Manuelli and Peter Rossi [1996], "On the Optimal Taxation of Capital Income," Journal of Economic Theory, forthcoming.

[19] Judd, Kenneth [1995a], "The Optimal Tax Rate for Capital Income is Negative," Hoover Institution, Stanford University, April.

[20] Judd, Kenneth [1995b], "Optimal Taxation and Spending in General Competitive Growth Models," Hoover Institution, Stanford University, November.

[21] Lucas, Robert E. Jr. [1988], "On the Mechanics of Economic Development," Journal of Monetary Economics 22, 3-42.

[22] Lucas, Robert E. Jr. [1990], "Supply-Side Economics: An Analytical Review," Oxford Economic Papers 42, 293-316.

[23] Milesi Ferretti, Gian Maria and Nouriel Roubini [1994a], "Optimal Taxation of Human and Physical Capital in Endogenous Growth Models," NBER Working Paper No. 4882, October. 
[24] Milesi Ferretti, Gian Maria and Nouriel Roubini [1994b], "Taxation and Endogenous Growth in Open Economies," NBER Working Paper No. 4881, October.

[25] Milesi Ferretti, Gian Maria and Nouriel Roubini [1995], "Growth Effects of Income and Consumption Taxes: Positive and Normative Analysis," NBER Working Paper No. 5317, October.

[26] Mulligan, Casey and Xavier Sala-i-Martin [1993], "Transitional Dynamics in Two-Sector Models of Endogenous Growth," Quarterly Journal of Economics, CVIII, August, 739-773.

[27] Pecorino [1993], "Tax Structure and Growth in a Model with Human Capital," Journal of Public Economics 52, 251-271.

[28] Shell, Karl [1967], "A Model of Inventive Activity and Capital Accumulation," in Shell (ed.) Essays in the Theory of Optimal Economic Growth, Cambridge, MA: MIT Press.

[29] Stokey, Nancy and Sergio Rebelo [1995], "Growth Effects of Flat-Rate Taxes," Journal of Political Economy 103, June, 419-450.

[30] Rebelo, Sergio [1991], "Long-Run Policy Analysis and Long-Run Growth," Journal of Political Economy 99, June, 500-521.

[31] Sargent, Thomas [1987], Macroeconomic Theory, 2nd edition, Academic Press.

[32] Zhu, Xiadong [1992], "Optimal Fiscal Policy in a Stochastic Growth Model," Journal of Economic Theory 58, December, 250-289. 